ARTICLE

DOI: $10.1038 / \mathrm{s} 41467-018-04333-2$

\title{
High temperature deformability of ductile flash-sintered ceramics via in-situ compression
}

Jaehun Cho ${ }^{1}$, Qiang Li i ${ }^{1}$, Han Wang ${ }^{1}$, Zhe Fan² ${ }^{2}$ Jin Li', Sichuang Xue ${ }^{1}$, K.S.N. Vikrant ${ }^{1}$, Haiyan Wang (1) 1,3, Troy B. Holland ${ }^{4}$, Amiya K. Mukherjee ${ }^{5}$, R. Edwin García ${ }^{1}$ \& Xinghang Zhang (D) ${ }^{1}$

Flash sintering has attracted significant attention as its remarkably rapid densification process at low sintering furnace temperature leads to the retention of fine grains and enhanced dielectric properties. However, high-temperature mechanical behaviors of flash-sintered ceramics remain poorly understood. Here, we present high-temperature (up to $600^{\circ} \mathrm{C}$ ) in situ compression studies on flash-sintered yttria-stabilized zirconia (YSZ). Below $400{ }^{\circ} \mathrm{C}$, the YSZ exhibits high ultimate compressive strength exceeding $3.5 \mathrm{GPa}$ and high inelastic strain $(\sim 8 \%)$ due primarily to phase transformation toughening. At higher temperatures, crack nucleation and propagation are significantly retarded, and prominent plasticity arises mainly from dislocation activity. The high dislocation density induced in flash-sintered ceramics may have general implications for improving the plasticity of sintered ceramic materials.

\footnotetext{
${ }^{1}$ School of Materials Engineering, Purdue University, West Lafayette, IN 47907, USA. ${ }^{2}$ Oak Ridge National Laboratory, Oak Ridge, TN 37830, USA. ${ }^{3}$ School of Electrical and Computer Engineering, Purdue University, West Lafayette, IN 47907, USA. ${ }^{4}$ Department of Mechanical Engineering, Colorado State University, Fort Collins, CO 80523, USA. ${ }^{5}$ Department of Chemical Engineering \& Materials Science, University of California, Davis, CA 95616, USA. These authors contributed equally: Jaehun Cho, Qiang Li. Correspondence and requests for materials should be addressed to H.W. (email: hwang00@purdue.edu) or to X.Z. (email: xzhang98@purdue.edu)
} 
C eramic materials have a variety of high-temperature applications, such as thermal barrier coatings for highthrust engines and turbines ${ }^{1}$. One promising candidate for thermal barrier coatings is yttria-stabilized zirconia (YSZ). YSZ offers one of the lowest thermal conductivities, $\sim 2.3 \mathrm{~W} / \mathrm{mK}$ at $\sim 1000^{\circ} \mathrm{C}^{2}$. Monolithic zirconia has monoclinic phase (space group $P 2_{1} / c$ ) at room temperature. However, the tetragonal phase (space group $P 4_{2} / n m c$ ) of zirconia can be stabilized by doping zirconia with $\mathrm{Y}_{2} \mathrm{O}_{3}, \mathrm{CeO}_{2}$, and $\mathrm{MgO}^{3,4}$. The discovery of martensitic phase transformation (from tetragonal to monoclinic phase) in $\mathrm{ZrO}_{2}$ has led to significant investigations on its deformability. The volume expansion $(\sim 4 \%)$ during martensitic phase transformations near the crack tips induced by an external stress can introduce compressive stress that can in turn retard crack propagation ${ }^{5,6}$. Therefore, YSZ provides new opportunities for various applications, including reliable thermal and environmental barrier coatings, solid oxide fuel cells, and shape memory devices, just to name a few ${ }^{1,7,8}$.

A majority of ceramic materials possess high strength but low toughness at low temperatures due to the lack of dislocationenabled deformability ${ }^{9}$. Certain nanostructured ceramics have shown high strength, wear resistance, and/or fracture toughness at elevated temperatures ${ }^{10-12}$. However, conventional sintering typically requires very high temperature and long sintering time and thus leads to significant grain coarsening ${ }^{13}$. Recently, it has been discovered that YSZ can be fully densified within a few seconds at a temperature much lower than conventional sintering temperature by a novel sintering technique named flash sintering $^{14}$. The ultrafast sintering technique enables the retention of nanograins and enhanced dielectric properties ${ }^{15}$. Flash sintering occurs by applying a ramp heating process at a constant heating rate under moderate electrical fields ${ }^{16-24}$. Once the temperature is above the onset of the flash temperature, under applied electrical field, a densification process takes place within a few seconds as evidenced by a sudden increase of electrical conductivity, accompanied with drastic increase in mass density ${ }^{25}$.

Prior studies on the mechanical behavior of YSZ showed superelasticity and shape memory effect at room temperature ${ }^{26-30}$. However, our understanding of the mechanical behaviors of smallscale YSZ specimens at elevated temperatures remains limited. Recently, Korte and Clegg showed that microcompression tests on small specimens could be carried out at an elevated temperature $\left(\sim 500^{\circ} \mathrm{C}\right)$ by heating the sample stage and indenter tip without a significant mechanical and thermal drift $(\sim 1 \mathrm{~nm} / \mathrm{s})^{31,32}$. Hightemperature micropillar compression technique enables the study on the temperature-dependent deformation mechanisms for brittle materials at elevated temperatures. Furthermore, the deformability of flash-sintered ceramics is largely unknown despite their intriguing microstructures, including the generation of a large number of charged defects during the flash-sintering process $^{25}$.

Here, we report an in situ micropillar compression study on the deformability of a flash-sintered $3 \mathrm{~mol} \%$ yttria stabilized zirconia (3YSZ) at elevated temperatures (up to $600^{\circ} \mathrm{C}$ ). The flash-sintered 3 YSZ contains abundant dislocations. The mechanical behaviors of the flash-sintered 3YSZ are highlighted by increased plasticity, and temperature-dependent transition of deformation mechanisms.

\section{Results}

Microstructural characterization. 3YSZ (TZ-3Y-E, Tosh corp., $40 \mathrm{~nm}$ ) was heated in a thermomechanical analyzer with platinum electrodes at a constant heating rate of $25^{\circ} \mathrm{C} / \mathrm{min}$ under an electrical field of $150 \mathrm{~V} / \mathrm{cm}$. The ultrafast densification process occurred at a furnace temperature of $1150-1200{ }^{\circ} \mathrm{C}$ in a few seconds (Supplementary Fig. 1), which is significantly lower compared to conventional sintering temperature of $\sim 1900^{\circ} \mathrm{C}$ to sinter 3 YSZ in just a few seconds ${ }^{33}$. The applied heat and electrical field were removed right after the onset of flash sintering to prevent grain growth. Even though the densification process of 3YSZ occurred at relatively low temperature, X-ray diffraction pattern shows a dominant tetragonal phase without evident monoclinic and cubic phases (Supplementary Fig. 2). Energy dispersive spectroscopy reveals that zirconium and yttrium are uniformly distributed throughout the grains, and zirconium is slightly deficient along grain boundaries (Supplementary Fig. 3). Figure 1a shows a scanning electron microscopy (SEM) image of an unpolished flash-sintered 3YSZ. An average grain size of 870 $\mathrm{nm}$ was determined by a systematic grain intercept method ${ }^{34}$ (Supplementary Fig. 4). However, bright-field transmission electron microscopy (TEM) micrograph reveals the existence of subgrains as shown in Fig. 1b. The average subgrain size is 159 $\mathrm{nm}$. The flash-sintered 3YSZ was densified to $98 \%$ of theoretical density with nanopores indicated by red arrows in Fig. 1b. Black arrows in Fig. $1 \mathrm{~b}$ indicate internal defects in grains generated during the flash sintering process. Deformation twinning which occurred frequently in bulk tetragonal zirconia ${ }^{35}$ was rarely observed in this study, presumably due to the ultrafine grain sizes.

Preexisting dislocations. Many of the defects in the grains are identified to be high-density dislocation networks (as shown in Supplementary Fig. 5). Furthermore, scanning TEM (STEM), bright-field and dark-field TEM micrographs in Fig. 1c-e show an array of dislocations inside a grain. Also, the dislocation arrays were observed frequently in the flash-sintered 3YSZ as shown in Fig. 1f-i and Supplementary Fig. 6. Meanwhile, 3YSZ synthesized at lower electric fields $(1.5$ and $15 \mathrm{~V} / \mathrm{cm})$ and at the same heating rate $\left(25^{\circ} \mathrm{C} / \mathrm{min}\right)$ was also prepared to study the effect of electric field on the dislocation generation. The relative density of $78 \%$ and $85 \%$ was achieved for the $1.5 \mathrm{~V} / \mathrm{cm}$ and $15 \mathrm{~V} / \mathrm{cm}$ specimens, respectively (Supplementary Fig. 1). The grain intercept method ${ }^{34}$ reveals average grain sizes of $59 \pm 7 \mathrm{~nm}$ and $57 \pm 9 \mathrm{~nm}$ for $3 Y S Z$ sintered under $1.5 \mathrm{~V} / \mathrm{cm}$ and $15 \mathrm{~V} / \mathrm{cm}$, respectively. The TEM studies reveal little dislocations or dislocation arrays in these specimens (Supplementary Fig. 7).

In situ microcompression tests. Micropillars with $\sim 3 \mu \mathrm{m}$ in diameter and $\sim 6 \mu \mathrm{m}$ in height were fabricated using the focused ion beam (FIB) technique on the flash-sintered 3YSZ. Given that the average subgrain size of the specimen is $\sim 160 \mathrm{~nm}$, each pillar contains more than 5000 subgrains. Thus, the mechanical behaviors of the micropillars are a good representation of a large number of grains. Uniaxial in situ microcompression tests on the micropillars were carried out from room temperature to $600{ }^{\circ} \mathrm{C}$ at a constant strain rate of $5 \times 10^{-3} \mathrm{~s}^{-1}$ inside an SEM microscope with partial unloadings at strains of 0.5 and $1 \%$, to evaluate the apparent elastic modulus at each test temperature (Supplementary Movies 1-3). Figure 2 shows snapshots of SEM images taken during the in situ compression tests of micropillars at different strain levels at room temperature and $400{ }^{\circ} \mathrm{C}$. Micropillars compressed at room temperature sustained a strain up to $\sim 8 \%$ without crack formation, and then experienced brittle catastrophic fracture at a strain of $\sim 9 \%$. For micropillars tested at 400 ${ }^{\circ} \mathrm{C}$, cracks nucleated at smaller strain, $\sim 4 \%$, and a greater crack density was observed when compared to the specimens tested at room temperature. Meanwhile, cracks propagated downward gradually along the axial (loading) direction, but no catastrophic failure was observed. Figure $2 \mathrm{i}$ shows that the maximum flow stress exceeds $3.5 \mathrm{GPa}$ in specimens tested at room temperature; 

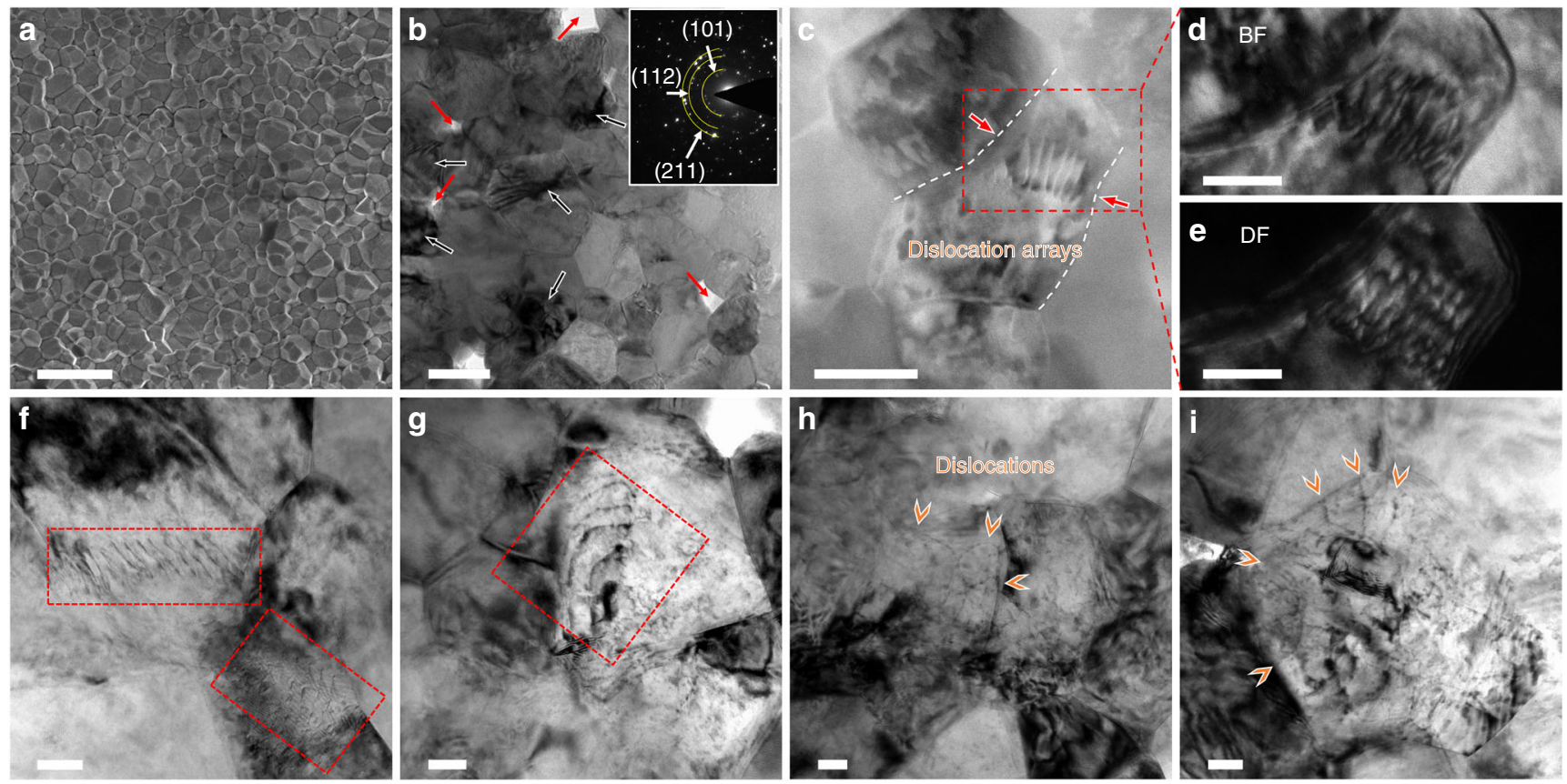

Fig. 1 Microstructure of flash-sintered 3YSZ. a SEM images of the unpolished flash-sintered 3YSZ. The average particle size is $\sim 1 \mu \mathrm{m}$. Scale bar, $3 \mu \mathrm{m}$. b Bright-field TEM micrograph showing subgrains with grain boundaries and defects generated during flash sintering (labeled by black arrows), and nanopores ( $1.4 \%$ ) (indicated by red arrows). The inserted SAD pattern shows diffraction rings. Scale bar, 200 nm. c A STEM micrograph showing a dislocation array inside a grain in the flash-sintered 3YSZ. The dislocation array was generated in a bottleneck region of the grain as indicated by red arrows. Scale bar, $100 \mathrm{~nm}$. d, e Bright-field (BF) and dark-field (DF) TEM micrographs showing the dislocation array in the boxed region in c. Scale bar, 50 $\mathrm{nm}$. f-i Numerous BF TEM images of the flash-sintered 3YSZ showing the existence of dislocations and dislocation arrays in grains. Scale bar, $50 \mathrm{~nm}$
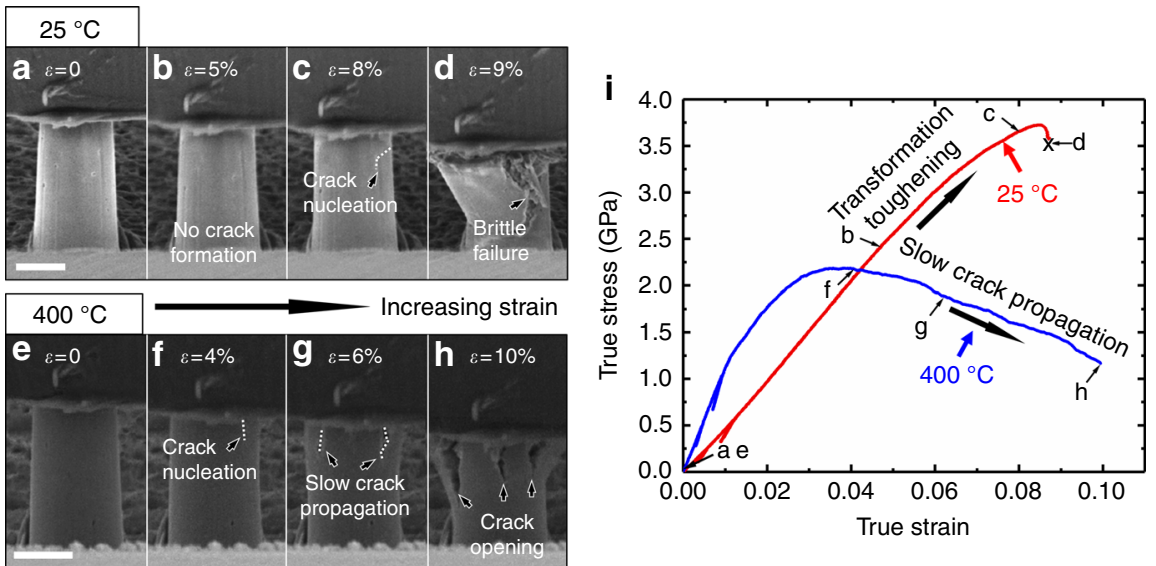

Fig. 2 Uniaxial in situ microcompression tests on the flash-sintered $3 Y S Z$ at room temperature and $400^{\circ} \mathrm{C}$ at a constant strain rate of $5 \times 10^{-3} \mathrm{~s}^{-1}$. a-d SEM images during in situ compression test of a micropillar at different strain levels at $25^{\circ} \mathrm{C}$. No crack can be detected until a true strain of $8 \%$. At the strain of $\sim 9 \%$, the pillar experienced brittle catastrophic fracture. Scale bar, $2 \mu \mathrm{m}$. e-h For micropillars tested at $400{ }^{\circ} \mathrm{C}$, cracks nucleated at smaller strain, $\sim 4 \%$. Crack density increased with compressive strain. However, cracks propagated downward gradually and slowly without catastrophic failure. Scale bar, $2 \mu \mathrm{m}$. $\mathbf{i}$ The corresponding true stress-strain curve shows that the flow stress exceeds $3.5 \mathrm{GPa}$ for pillars tested at $25^{\circ} \mathrm{C}$. In comparison, the pillar tested at $400^{\circ} \mathrm{C}$ has a flow stress of $2 \mathrm{GPa}$ and higher elastic modulus determined from partial loading and unloading experiments

whereas the peak stress reaches $2 \mathrm{GPa}$ for specimens tested at $400{ }^{\circ} \mathrm{C}$ at a true strain of $4 \%$, and the stress decreases thereafter.

Temperature dependence of deformation mechanisms. Figure $3 \mathrm{a}-\mathrm{j}$ compares SEM images of flash-sintered $3 \mathrm{YSZ}$ micropillars before and after microcompression tests at various temperatures. It shows that $400^{\circ} \mathrm{C}$ is a fiducial temperature at which fracture mechanisms change drastically. At 25 and $200^{\circ} \mathrm{C}$, the micropillars, though they sustained a large strain, fractured in a brittle (catastrophic) manner. On the other hand, when tested between 400 to $600^{\circ} \mathrm{C}$, multiple cracks initiated and propagated from the top surface down into the pillars, leading to the formation of cauliflower morphologies at the top of the pillars (Fig. 3f, $\mathrm{h}, \mathrm{j}$ ). As the test temperature rose, a prominent decrease of crack density and propagation was observed, implying that a new deformation mechanism began to govern the inelastic behavior of the pillars at $400^{\circ} \mathrm{C}$ and beyond. Figure $3 \mathrm{k}$ compares 

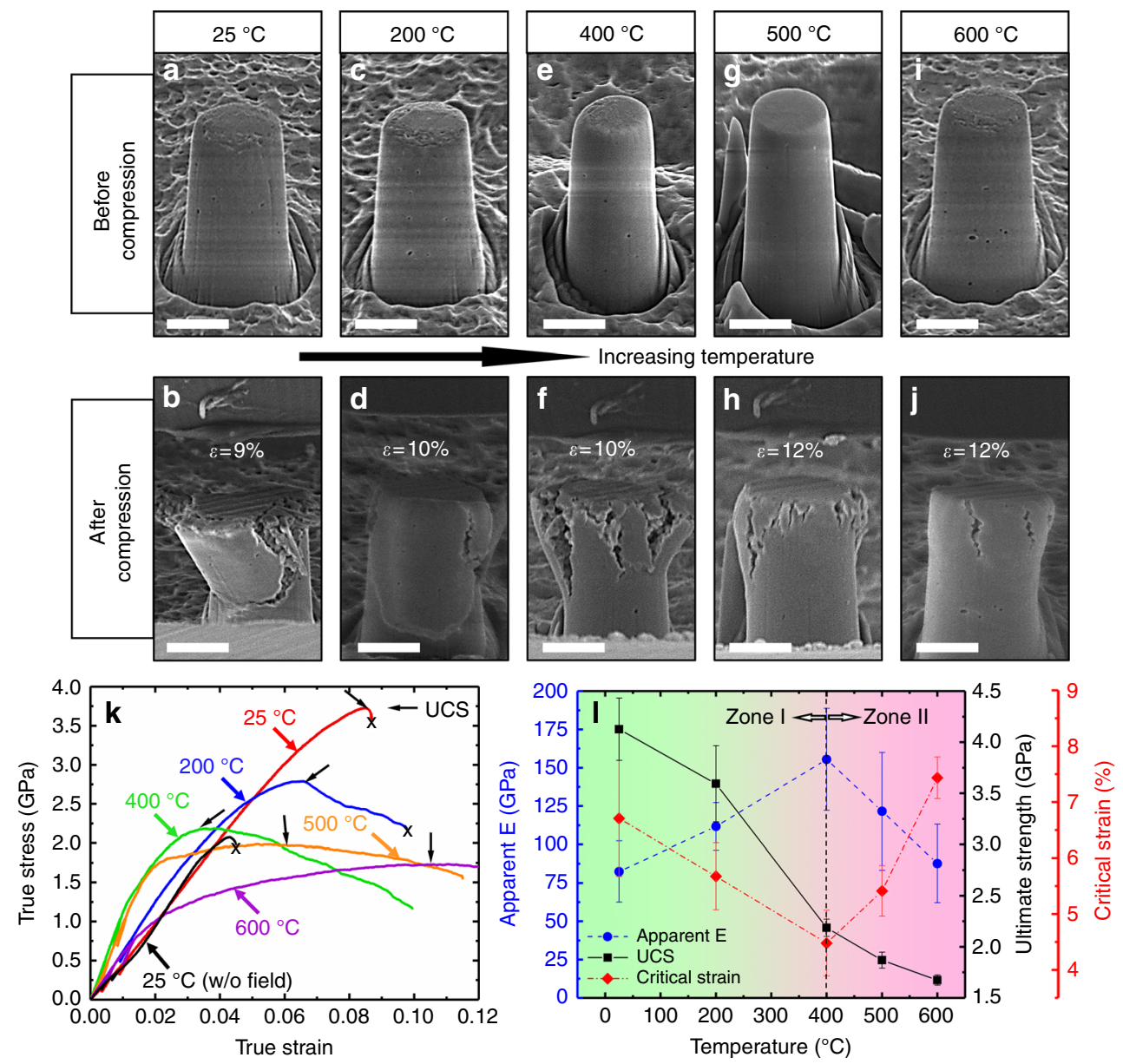

Fig. 3 SEM images of the flash-sintered 3YSZ micropillars before and after compression tests from 25 to $600^{\circ} \mathrm{C}$ and corresponding mechanical properties. a-d When tested at $200^{\circ} \mathrm{C}$ and below, the pillar fractured in a brittle manner (into two major sections) at very large true strain. Scale bar, $2 \mu \mathrm{m}$. e-j When tested at $400-600^{\circ} \mathrm{C}$, multiple cracks formed and propagated slowly into the pillars, leading to formation of the cauliflower type of pillar tops. At $600{ }^{\circ} \mathrm{C}$ crack density and propagation distance were substantially reduced. Scale bar, $2 \mu \mathrm{m}$. $\mathbf{k}$ Corresponding true stress-strain curves of pillars tested at different temperatures. Black arrows indicate the ultimate compressive strength (UCS) of the pillars. Partial unloadings at 0.5 and $1 \%$ strains were performed to investigate the apparent elastic moduli of pillars tested at different temperatures. A stress-strain curve for 3 YSZ sintered without the electrical field is shown as reference. I Ultimate compressive strength (UCS) decreases monotonically with increasing test temperature. The elastic modulus increases with test temperature up to $400^{\circ} \mathrm{C}$ and decreases thereafter. Meanwhile, the critical strain at which the first crack nucleates decreases with temperature to a minimum of $4.5 \%$ at $400^{\circ} \mathrm{C}$ and increases thereafter to $7.5 \%$ when tested at $600^{\circ} \mathrm{C} .400{ }^{\circ} \mathrm{C}$ is the onset temperature where a different inelastic deformation mechanism begins to operate. Zone 1 represents phase transformation toughening from room temperature to $400{ }^{\circ} \mathrm{C}$. Zone 2 corresponds to dislocation creep dominant plasticity above $400^{\circ} \mathrm{C}$

corresponding stress-strain curves of pillars tested at different temperatures with black arrows, indicating the ultimate compressive strength (UCS) of the pillars. Five true stress-true strain curves were obtained for reproducibility tests at each temperature (shown in Supplementary Fig. 8). The UCS of the flash-sintered 3YSZ decreases monotonically with increasing test temperature as shown in Fig. 31. However, elastic modulus (measured from a series of partial unloading experiments) first increases with test temperature up to $400^{\circ} \mathrm{C}$ and decreases thereafter. The critical strain for the nucleation of cracks decreases with increasing test temperature, reaches a minimum at $400{ }^{\circ} \mathrm{C}$, and then increases to $\sim 7.5 \%$ at $600{ }^{\circ} \mathrm{C}$. Meanwhile, $3 \mathrm{YSZ}$ was also sintered without electric field at a constant heating rate of $25^{\circ} \mathrm{C} / \mathrm{min}$ to $1300^{\circ} \mathrm{C}$ and exhibited a failure stress of $2 \mathrm{GPa}$ and a failure strain of $4 \%$.

Martensitic transformations. Meanwhile, we carried out TEM experiments on the YSZ pillars after microcompression tests tested at room temperature. Supplementary Fig. $9 \mathrm{a}-\mathrm{b}$ shows the SEM micrographs of the pillar before and after compression test at room temperature. The pillar fractured at a flow stress of $\sim 4$ $\mathrm{GPa}$ and a strain of $\sim 6 \%$ (Supplementary Fig. 9c). Bright-field XTEM image of the fractured pillar clearly shows the fracture surface and embedded ultrafine grains (Supplementary Fig. 9d-f). Numerous grains in vicinity of the fracture surface were examined carefully. The diffraction pattern of grain 1 (Supplementary Fig. 9g) obtained along the [101] zone axis was indexed to be a monoclinic phase (JCPDS\#37-1484). The interplanar spacing of the (111) planes is measured to be $0.279 \mathrm{~nm}$, consistent with the theoretical value of $0.284 \mathrm{~nm}$. Grains 2 and 3 were examined along respective zone axis of $[1 \overline{3} 2]$ and [112] and indexed to be monoclinic zirconia phase. These studies show that the tetragonal-to-monoclinic phase transition indeed took place during the compression tests.

Cyclic loading tests. Thirty cyclic loading and partial unloading tests were carried out at a strain rate of $5 \times 10^{-3} \mathrm{~s}^{-1}$ at room temperature and $400{ }^{\circ} \mathrm{C}$ as shown in Fig. 4. Holding segments prior to unloading for $1 \mathrm{~s}$ (during which displacement remains 

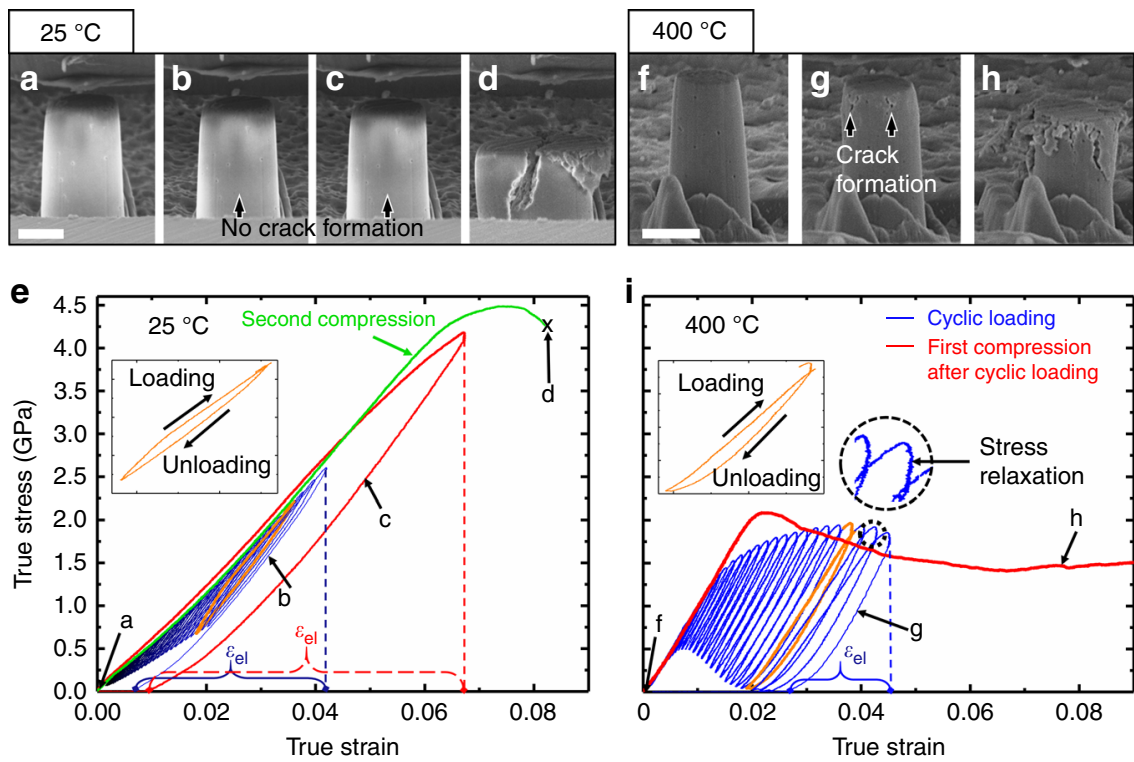

Fig. $4 \mathrm{Cyclic}$ loading and subsequent monotonic compression tests at a strain rate of $5 \times 10^{-3} \mathrm{~s}^{-1}$ at 25 and $400^{\circ} \mathrm{C}$ and the corresponding stress-strain curves. a, f SEM images of micropillars before cyclic loading tests. Scale bar, $2 \mu \mathrm{m}$. $\mathbf{b}, \mathbf{g}$ SEM micrographs of micropillars after 30 cyclic loading tests. The cyclic stress-strain curves are shown as blue curves in $\mathbf{e}$ and $\mathbf{i}$. c, $\mathbf{h}$ After the first monotonic compression tests highlighted in red curves. $\mathbf{d}$ After the second monotonic compression test highlighted in green. The 27th loading-unloading curves at each temperature shown in orange color and enlarged in the inserted stress-strain curves clearly show the hysteresis loops. The upper portion of a loading-unloading curve is enlarged in a circle to illustrate the stress relaxation for $1 \mathrm{~s}$ of holding at $400^{\circ} \mathrm{C}$

constant) were added. First, 30 cyclic loadings (with increasing strain in each cycle) up to a strain of $4 \%$ were conducted with partial unloading to half of the maximum applied strain in each cycle in order to maintain a solid contact between the diamond tip and pillar. No crack was observed for the specimens tested at room temperature during the cyclic tests, and the pillar exhibited a significant amount of recoverable strain during unloading (Fig. 4b). After cyclic tests, a monotonic compression test (highlighted by a red curve in Fig. 4e) was conducted on the same micropillar up to a strain of $7 \%$. The pillar exhibited $\sim 6 \%$ recoverable and $\sim 1 \%$ irrecoverable strain without crack (Fig. $4 \mathrm{c}$ ). The same pillar then experienced a catastrophic failure in a succeeding monotonic compression test (Fig. $4 \mathrm{~d}$ ) at a strain of $8 \%$, shown by a green curve in Fig. 4e. In comparison, YSZ subjected to cyclic loading tests at $400^{\circ} \mathrm{C}$ (Fig. 4i) showed much less recoverable strain than that tested at room temperature. Also, small cracks formed (as shown in Fig. $4 \mathrm{~g}$ ) at a strain of $4 \%$ during the cyclic loading test. The subsequent monotonic microcompression test on the same pillar highlighted as a red curve in Fig. 4i shows that the pillar exhibited a UCS of $2 \mathrm{GPa}$, and a residual strength of 1.5 $\mathrm{GPa}$ at a strain of $9 \%$, and multiple cracks formed after compression tests (Fig. 4h).

\section{Discussion}

In general, dislocations are rare in ceramics as the strong covalent and ionic bond greatly discourages the formation of dislocations. However, TEM studies herein show ample evidence for the formation of high-density dislocations in flash-sintered 3YSZ. Also, dislocation arrays are frequently observed near triple junctions. It is likely that a large stress concentration (gradient) develops near triple junctions during the rapid grain growth process. Significant mass (atomic) transport occurs during the flash-sintering process to fill in the voids among grains/particles during a very short sintering time (several seconds). The high rate (4-5 orders of magnitude faster than conventional sintering) of mass transport and flow near triple junctions may lead to substantial plastic deformation (enabled by high-density dislocation arrays as shown in Fig. 1c) during flash sintering ${ }^{25}$. This assertion coincides with TEM studies of 3 YSZ sintered under 1.5 and $15 \mathrm{~V} / \mathrm{cm}$, which display insignificant grain growth and little dislocations. Rapid grain growth and large electric field may play a significant role in producing dislocations and their arrays by generating the internal stress during flash sintering. The electric field of 1.5 and $15 \mathrm{~V} / \mathrm{cm}$ is insufficient to induce dislocations in 3YSZ. Interestingly, intragranular dislocations and dislocation entanglement in 3YSZ have been observed at an ultrahigh temperature, $1400^{\circ} \mathrm{C}$, during tensile creep tests at $50 \mathrm{MPa}^{36}$. In the current study, the generation of intragranular dislocations, their arrays and entanglement near triple junctions may strongly depend on stress and high strain rate plastic flow during flash sintering. The shear stresses allowing dislocation pile-up in $3 \mathrm{YSZ}$ range from 350 to $1260 \mathrm{MPa}$ based on the lattice dislocation pile-up model ${ }^{37}$ :

$$
\tau=\frac{G b}{2 L} N
$$

where $G$ is the shear modulus, $b$ is the Burgers vector, $N$ is the number of intragranular dislocations in the pile-up within a grain, and $L$ is the length of dislocation pile-ups. From TEM measurement of dislocation separation distances in the pile-ups, $\sim 20 \mathrm{~nm}$, in flash-sintered 3YSZ, the shear stress during flash sintering is estimated to be $\sim 1230 \mathrm{MPa}$ (by taking $G=65 \mathrm{GPa}$ and $b$ for $<110>$ type lattice dislocation $=3.6 \times 10^{-10} \mathrm{~m}$ ), which is within the range that can form dislocation arrays in $3 \mathrm{YSZ}$ at elevated temperatures during flash sintering. The dislocation density in many grains reaches as high as $\sim 2-3 \times 10^{12} \mathrm{~m}^{-2}$, comparing to the typical density of $\sim 10^{8}-10^{10} \mathrm{~m}^{-2}$ in a majority of ceramics ${ }^{38}$. These high-density dislocations play a vital role on the deformability of the flash-sintered 3YSZ tested at elevated temperatures. It is well known that dislocation glide is unlikely to take place in bulk ceramic materials at room temperature unless applying a confinement pressure via hydrostatic or gaseous medium $^{31}$. However, at microscales, plastic deformation of 
certain ceramics by glide of dislocations has been observed ${ }^{39,40}$. Camposilvan et al. investigated the plasticity of conventionally sintered YSZ at small scales at room temperature and speculated that dislocation activity along with transformation-induced plasticity at a higher stress level (without showing direct evidence of dislocations) may be a possible inelastic deformation mechanism for $\mathrm{YSZ}^{28}$. Our finite-element method analysis on stress distribution for dislocations in polycrystalline YSZ further supports this assertion and shows that shear stress concentration near-grain boundaries and triple junctions induces the nucleation and migration of dislocations, thereby facilitating the plastic deformation of YSZ (Supplementary Figs. 10 and 11 and Supplementary Methods).

A strain of $\sim 8 \%$ for stabilized zirconia owing to martensitic transformation-induced plasticity has been previously reported ${ }^{8,27-30}$. However, micropillars exhibiting such a large strain were often limited to single and oligocrystalline structures to minimize internal mismatch stresses during martensitic transformation. The micropillars of the flash-sintered 3YSZ consist of subgrains, $\sim 160 \mathrm{~nm}$ in diameter, much smaller than the diameter of the micropillars $(3 \mu \mathrm{m})$. Thus, the large $\sim 8 \%$ inelastic flow may arise from not only transformation-induced plasticity, but also dislocation activity especially at higher stress level.

For micropillars tested at $400^{\circ} \mathrm{C}$, cracks nucleated at smaller strain, $\sim 4 \%$, due to the lack of martensitic transformation toughening. At elevated temperatures, the metastable tetragonal phase begins to thermally transform into a mixture of tetragonal and cubic phase, degrading the deformability of the flash-sintered 3 YSZ by transformation toughening ${ }^{37}$. However, at $400{ }^{\circ} \mathrm{C}$, cracks initiated from the top surface of the micropillar propagate downward gradually and slowly without catastrophic failure unlike the brittle catastrophic fracture of micropillars tested at room temperature. The prominent variation of fracture morphology of the deformed pillars implies that a new inelastic deformation mechanism supersedes martensitic transformation toughening as temperature rises. In the conventionally sintered bulk YSZ system, it is known that the $700-800{ }^{\circ} \mathrm{C}$ temperature range favors other mechanisms (grain boundary sliding, ferroelastic domain switching, and/or dislocation activity) as a substitute to martensitic transformation ${ }^{41}$. However, the flashsintered YSZ contains nanograins, oxygen vacancies ${ }^{15}$, and abundant preexisting dislocations, which may result in the early activation of other inelastic deformation mechanisms at $400{ }^{\circ} \mathrm{C}^{42}$. It is worth mentioning that the critical strain for the pillars compressed at $200{ }^{\circ} \mathrm{C}$ is still high $(\sim 6 \%)$. Catastrophic failure of pillars was also observed for specimens tested at $200^{\circ} \mathrm{C}$, and transformation toughening-induced plasticity remains the dominant inelastic deformation mechanism of the flash-sintered 3 YSZ.

At an even greater test temperature, the martensitic phase transformation toughening is gradually replaced by the activation of a new inelastic deformation mechanism. Basically, the critical strain at which the first crack occurs decreases with increasing test temperature and reaches a minimum at $\sim 400{ }^{\circ} \mathrm{C}$ as can be seen in Fig. 3i. The earlier occurrence of cracks at an elevated temperature (at lower critical strain than that at room temperature) implies a lack of transformation toughening. The critical strain for the onset of crack propagation increases when the test temperature is $>400{ }^{\circ} \mathrm{C}$. Furthermore, in contrast to the cracktriggered catastrophic failure in low-temperature specimens $(25$ and $\left.200^{\circ} \mathrm{C}\right)$, cracks in high-temperature specimens $\left(\geq 400^{\circ} \mathrm{C}\right)$ propagate slowly and are more uniformly distributed in the top portion of the deformed pillar, leading to the dilated cauliflower morphology. The slow crack propagation speed indicates enhanced compressive ductility at elevated temperature. As phase transformation toughening is less likely to operate at high temperatures, the enhanced plasticity of YSZ may arise from deformation mechanisms, such as dislocation creep and/or grain boundary sliding. The high-density dislocations in flash-sintered specimens suggest that dislocation power creep type of mechanism is highly likely. Meanwhile, the small grains retained in the flash-sintered specimens may promote grain boundary sliding as a favorable deformation mechanism. Therefore, $400{ }^{\circ} \mathrm{C}$ is the brittle-to-ductile transition temperature for flash-sintered YSZ, a much lower value than the one reported for conventionally sintered or single-crystal YSZ systems $\left(\sim 800^{\circ} \mathrm{C}\right)^{43}$.

The apparent elastic moduli of tested YSZ are lower than the theoretical values $(210 \mathrm{GPa})$ at all test temperatures. It is well known that the underestimation of elastic modulus in the microcompression tests can be attributed to taper angle of the pillars, misalignment between the tips and pillars, and stress concentration on the top surface of the pillars ${ }^{28}$. Taking the underestimation into consideration, it is still surprising that the apparent elastic modulus of the flash-sintered $3 \mathrm{YSZ}$ increases with temperature and reaches a maximum at $400{ }^{\circ} \mathrm{C}$ (Fig. 3i). This is because: (a) the dominant phase of $3 \mathrm{YSZ}$ at room temperature is metastable tetragonal phase of zirconia (Supplementary Fig. 2) and the elastic modulus of tetragonal phase is known to be lower than that of monoclinic and cubic phase ${ }^{44,45}$. When temperature increases, an increasing portion of tetragonal zirconia undergoes transformation to stable tetragonal and cubic phase, which may lead to the slight increase of the apparent elastic modulus ${ }^{46}$. (b) Ceramic materials retaining superelasticity usually exhibit lower elastic modulus due to the strain burst. It follows that the larger elastic modulus observed at elevated temperatures is an indication of suppression of the martensitic phase transformation due to thermodynamically reinforced stability of tetragonal phase $\mathrm{u}^{47,48}$. The total free energy change for martensitic transformation per unit volume $\left(\Delta U_{0}\right)$ can be expressed as ${ }^{47}$,

$$
\Delta U_{0}=\Delta U_{\mathrm{c}}+\Delta U_{\mathrm{e}}+\Delta U_{\mathrm{s}}-\Delta U_{\mathrm{I}}
$$

where $\Delta U_{\mathrm{c}}$ is the chemical free energy change, $\Delta U_{\mathrm{e}}$ the elastic energy change associated with volume expansion of tetragonal zirconia constraint by matrix, $\Delta U_{\mathrm{s}}$ the interface energy change (negligible), and $\Delta U_{I}$ the change in free energy associated with an external applied stress. This mechanical term should be larger than the first three terms on the right-hand side for martensitic transformation to occur. When the chemical free energy term $\left(\Delta S_{\mathrm{m}}\left(M_{\mathrm{s}}-T\right)\right)$ and additional free energy change $\left(\Delta S_{\mathrm{m}}\left(M_{\mathrm{s}}-T_{0}\right)\right)$ due to the presence of dopant are taken into account ${ }^{48}$, the total free energy change as a function temperature is given by,

$$
\Delta U_{0}=\Delta S_{\mathrm{m}}\left(M_{\mathrm{s}}-T\right)-\Delta U_{\mathrm{I}}
$$

where $\Delta S_{\mathrm{m}}$ is entropy change associated with martensitic transformation and $M_{\mathrm{s}}$ is the martensitic start temperature. When $M_{\mathrm{s}}=T$, spontaneous martensitic transformation takes place without the external stress. As test temperature increases, Eq. (3) shows that the chemical energy change also increases (note that entropy term is negative value), thereby requiring a larger mechanical term to overcome free energy barrier for martensitic transformation to occur.

The higher temperature $\left(T>400^{\circ} \mathrm{C}\right)$ weakens the interatomic bonds and thus reduces the elastic modulus, and high-density flash-sintered dislocations significantly contribute to the plasticity of $3 \mathrm{YSZ}$ as manifested by the increasing critical strain to nearly $7.5 \%$ before the observation of cracks at $600{ }^{\circ} \mathrm{C}$. In summary, elastic modulus, critical strain, and fracture behavior of flashsintered $3 \mathrm{YSZ}$ at each test temperature indicate that $400{ }^{\circ} \mathrm{C}$ is the temperature beyond which inelastic deformation mechanism of 
the flash-sintered YSZ changes prominently. Therefore, Zone 1 in Fig. $3 \mathrm{i}$ corresponds to transformation toughening-dominated region below $400{ }^{\circ} \mathrm{C}$; whereas, Zone 2 is associated to dislocation activity and presumably grain boundary sliding dominant region above $400^{\circ} \mathrm{C}$.

An indirect way to confirm martensitic transformation is to check the existence of reverse transformation ${ }^{9}$. As shown in Fig. 4a-e, a significant amount of recoverable strain was observed during partial unloading owing to reverse transformation at room temperature. Furthermore, hysteresis loops appear as strain increases. The area of the hysteresis loop tends to increase as stress and strain both increase. The appearance of hysteresis loops may be attributed to reverse transformation and reopening of closed pores in the flash-sintered $3 \mathrm{YSZ}^{49}$. The pillar after the cyclic loading test experiences $1 \%$ plastic strain, but still does not exhibit cracks as can be seen in Fig. $4 \mathrm{~b}$. It is worth mentioning that the stress-strain curves show stronger linearity as the cyclic compression tests are conducted on the same pillar. The stress-strain curve for the second monotonic test shows the highest linearity compared to the cyclic loading and the first monotonic compression test. This implies that martensitic transformation begins to concede as consecutive compression tests are carried out on the same pillar because part of the transformed monoclinic phase does not revert to tetragonal as the load on the pillar is removed ${ }^{50}$. Cyclic loading tests at $400{ }^{\circ} \mathrm{C}$ show significantly less recoverable strain than the room temperature tests due primarily to the lack of transformation toughening, but the hysteresis loop remains visible presumably due to reopening of the microcracks and pores. An increase of crack density and slow crack propagation seem to prevent the pillars from undergoing brittle fractures and the pillar achieves a residual strength of $1.5 \mathrm{GPa}$. Furthermore, stress relaxation measured during the holding segment ( $1 \mathrm{~s}$ for cycles) is observed at both room temperature and $400{ }^{\circ} \mathrm{C}$ (Supplementary Fig. 12). Room temperature test exhibits the same amount of stress relaxation during holding regardless of the overall strain. The formation of new microcracks and strain energy reduction in the pillar may result in the stress relaxation at room temperature ${ }^{51}$. On the other hand, a significant increase of stress relaxation (the absolute value of stress reduction) is observed at $400{ }^{\circ} \mathrm{C}$ and the stress relaxation increases as the pillar undergoes plastic flow. Stress relaxation at high temperature is normally due to high temperature and stress-induced sintering and closure of pores ${ }^{51}$. However, this mechanism is less likely at the low temperature $\left(400^{\circ} \mathrm{C}\right)$. Thus, stress relaxation taking place at $400^{\circ} \mathrm{C}$ may be mainly contributed by a thermally activated inelastic process such as the effect of grain boundary sliding, and/or diffusional creep of dislocations generated during the ultrafast sintering process. Another possible explanation is transient dislocation movement during the holding segment triggered by dislocation gliding, which is more likely to happen at elevated temperatures ${ }^{28}$. Thus, the observation of stress relaxation may indicates that the dislocation activity contributes to deformability of flash-sintered 3YSZ together with grain boundary sliding and/or diffusion-induced inelastic mechanism above $400{ }^{\circ} \mathrm{C}$. The proposed relaxation mechanisms are all thermally activated phenomenon and time is an important variable. To better understand the inelastic mechanism activated at elevated temperature, systematic strain rate jump microcompression tests are needed in future studies.

In conclusion, the first in situ study on mechanical behavior of flash-sintered YSZ was performed inside SEM at elevated temperatures up to $600^{\circ} \mathrm{C}$. At room temperature, YSZ micropillars sustain giant strain $(\sim 8 \%)$ comparing with its bulk counterpart $(\sim 2 \%)$ due to the stress-induced martensitic transformation toughening. However, the pillars fracture catastrophically after the nucleation of cracks. In comparison, a brittle-to-ductile transition of fracture mode is observed at $400{ }^{\circ} \mathrm{C}$ in flash-sintered
YSZ, much lower than the $\sim 800^{\circ} \mathrm{C}$ reported in conventional bulk YSZ. The enhanced plasticity at elevated temperatures arises from the transition from phase transformation toughening to dislocation creep, as the dominant inelastic deformation mechanism due to the existence of a high density of dislocations in flash-sintered YSZ and/or to early initiation of grain boundary sliding of ultrafine grains. This study provides the first evidence on superior mechanical properties of flash-sintered ceramics by using in situ nanomechanical testing technique at elevated temperatures and establishes an important way to fundamentally understand the densification and mechanical properties of ceramics.

\section{Methods}

Flash sintering. Flash sintering was performed on a custom-modified thermomechanical testing system (SETSYS Evolution, SETARAM Instrumentation). Specimens with a diameter of $5 \mathrm{~mm}$ and a thickness of $2 \mathrm{~mm}$ prepared by using commercially available 3 YSZ (TZ-3Y-E, Tosoh corp., $40 \mathrm{~nm}$ particle size) were sandwiched between two platinum electrodes. An alumina rod was utilized to apply minimum pressure (a few $\mathrm{kPa}$ ) to ensure rigid contact between the electrodes and sample. A DC power of various voltage was applied to achieve electric field of 1.5 , 15 , and $150 \mathrm{~V} / \mathrm{cm}$ with a constant heating rate of $25^{\circ} \mathrm{C} / \mathrm{min}$ (maximum temperature was set to $1300^{\circ} \mathrm{C}$ ). The experiment was performed in the presence of air. After the onset of flash, the system was switched from the voltage-control mode to a current-control mode. The experiment was terminated right after switching to current-control mode to prohibit grain growth. The linear shrinkage of the samples was measured by a dilatometer.

TEM sample preparation. Plan-view TEM samples of flash-sintered 3YSZ were prepared through the conventional approach, which includes manual grinding, polishing, dimpling, and final polishing in an ion milling system (PIPS II, Gatan) Low energy ion polishing $(2 \mathrm{kV})$ was used to minimize ion milling-induced damage. An FEI Talos 200X TEM/STEM with ChemiSTEM technology (X-FEG and SuperX EDS with four silicon drift detectors) operated at $200 \mathrm{kV}$ was used in this study for microstructure characterization and energy-dispersive X-ray spectroscopy (EDS) chemical mapping.

Microcompression test. Micropillars of flash-sintered 3YSZ with $\sim 3 \mu \mathrm{m}$ in diameter and a diameter-to-height aspect ratio of 1:3-1:2 were prepared using focused ion beam (FEI quanta 3D FEG) and a series of concentric annular milling and polishing with progressively de-escalated currents were adopted to reduce tapering angle. Micropillar compression experiments have been performed using a Hysitron PI $88 \times$ R PicoIndenter equipped with a piezoelectric actuator on the capacitive transducer that enables the collection of force-displacement data inside a scanning electron microscope (FEI quanta 3D FEG). Moreover, a $20 \mu \mathrm{m}$ diamond flat punch tip designed for high-temperature compression experiments was used to conduct in situ compression experiments and the geometric variation of micropillars was synchronized to evolving force-displacement curve. For high temperature in situ compression setups, the flat punch was fastened to probe heater and the specimens were clamped by a V-shaped molybdenum to a ceramic heating stage. The temperature on two heating terminals were simultaneously ramped up at a rate of $10{ }^{\circ} \mathrm{C} / \mathrm{min}$ and isothermally preserved for $3 \mathrm{~min}$ before implementing every single compression experiment to eliminate the thermaldriven drifts on both probe and stage sides. An average drift rate of $0.2-0.5 \mathrm{~nm} / \mathrm{s}$ was estimated in preloading process for $45 \mathrm{~s}$ and the estimated force noise level is less than $8 \mu \mathrm{N}$ prior to compression. An overestimation of specimen displacement during the compression test induced by a displacement associated with the measuring instrument (machine compliance) was systematically measured during in situ SEM studies and corrected.

Finite-element analysis. The microstructure shown in Supplementary Fig. 3a with three different grain orientations was subjected to a compression of $-200 \mathrm{MPa}$ in the in-plane vertical direction, while the bottom boundary was fixed, and the outof-plane state of stress was set to plane strain conditions. Material properties are summarized in Table 1. Assigned Euler angle orientations are, for the bottom grain, $(\alpha, \beta, \gamma)=(0,0,0)$, for the top-right grain, $(\alpha, \beta, \gamma)=(0,45,0)$ and for the top-left grain, $(\alpha, \beta, \gamma)=(45,45,0)$. Euler angles operations are: first rotate angle $\beta$ degrees about the $z$-axis, then rotate $\alpha$ degrees about the $y$-axis, and finally rotate $\gamma$ degrees about new $z$-axis. The mechanical equilibrium state of the polycrystalline was

Table 1 Elastic properties of tetragonal zirconia 46

\begin{tabular}{|c|c|c|c|c|c|}
\hline $\mathrm{C}_{11}(\mathrm{GPa})$ & $\mathrm{C}_{12}(\mathrm{GPa})$ & $\mathrm{C}_{13}(\mathrm{GPa})$ & $C_{33}(\mathrm{GPa})$ & $\mathrm{C}_{44}(\mathrm{GPa})$ & $\mathrm{C}_{66}(\mathrm{GPa})$ \\
\hline 395 & 26 & 105 & 326 & 42 & 56 \\
\hline
\end{tabular}


solved using $\mathrm{OOF} 2^{52}$, an open source implementation of the finite-element method. The relative numerical tolerance was set to $1 \times 10^{-10}$. The simulation used $40 \mathrm{~GB}$ of RAM and a wall time of $\sim 4 \mathrm{~h}$ (See Supplementary Methods for detailed methodology).

Data availability. The data that support the findings of this study are available from the corresponding author on reasonable request.

Received: 4 September 2017 Accepted: 18 April 2018

Published online: 25 May 2018

\section{References}

1. Padture, N. P., Gell, M. \& Jordan, E. H. Thermal barrier coatings for gasturbine engine applications. Science 296, 280-284 (2002).

2. Schlichting, K. W., Padture, N. P. \& Klemens, P. G. Thermal conductivity of dense and porous yttria-stabilized zirconia. J. Mater. Sci. 36, 3003-3010 (2001).

3. Garvie, R. C., Hannink, R. H. \& Pascoe, R. T. Ceramic steel? Nature 258, 703-704 (1975).

4. Porter, D. L. \& Heuew, A. H. Mechanisms of toughening partially stabilized zirconia (PSZ). J. Am. Ceram. Soc. 60, 183-184 (1977).

5. Reyes-Morel, P. E. \& Chen, I. W. Transformation plasticity of $\mathrm{CeO}_{2}$-stabilized tetragonal zirconia polycrystals: I, stress assistance and autocatalysis. J. Am. Ceram. Soc. 71, 343-353 (1988).

6. Witz, G., Shklover, V. \& Steurer, W. Phase evolution in yttria-stabilized zirconia thermal barrier coatings studied by rietveld refinement of X-ray powder diffraction patterns. J. Am. Ceram. Soc. 90, 2935-2940 (2007).

7. Singhal, S. C. Solid oxide fuel cells for stationary, mobile, and military applications. Solid State Ion. 152-153, 405-410 (2002).

8. Lai, A., Du, Z., Gan, C. L. \& Schuh, C. A. Shape memory and superelastic ceramics at small scales. Science 341, 1505-1508 (2013).

9. Ritchie, R. O. The conflicts between strength and toughness. Nat. Mater. 10, 817-822 (2011).

10. Cain, M. \& Morrell, R. Nanostructured ceramics: a review of their potential. Appl. Organomet. Chem. 15, 321-330 (2001).

11. Cahn, R. W. Nanostructured materials. Nature 348, 389-390 (1990).

12. Belmonte, $M$. Advanced ceramic materials for high temperature application. Adv. Eng. Mater. 8, 693-703 (2006).

13. Luo, J., Adak, S. \& Stevens, R. Microstructure evolution and grain growth in the sintering of 3Y-TZP ceramics. J. Mater. Sci. 33, 5301-5309 (1998).

14. Cologna, M., Rashkova, B. \& Raj, R. Flash sintering of nanograin zirconia in $<5 \mathrm{~s}$ at $850^{\circ}$ C. J. Am. Ceram. Soc. 93, 3556-3559 (2010).

15. M'Peko, J. C., Francis, J. S. C. \& Raj, R. Impedance spectroscopy and dielectric properties of flash versus conventionally sintered yttria-doped zirconia electroceramics viewed at the microstructural level. J. Am. Ceram. Soc. 96, 3760-3767 (2013).

16. Zhang, Y., Jung, J. I. \& Luo, J. Thermal runaway, flash sintering and asymmetrical microstructural development of $\mathrm{ZnO}$ and $\mathrm{ZnO}-\mathrm{Bi}_{2} \mathrm{O}_{3}$ under direct currents. Acta Mater. 94, 87-100 (2015).

17. Zhang, Y. \& Luo, J. Promoting the flash sintering of $\mathrm{ZnO}$ in reduced atmospheres to achieve nearly full densities at furnace temperatures of $<120{ }^{\circ} \mathrm{C}$. Scr. Mater. 106, 26-29 (2015).

18. Zhang, Y. et al. Probing the densification mechanisms during flash sintering of ZnO. Acta Mater. 125, 465-475 (2017).

19. Luo, J. The scientific questions and technological opportunities of flash sintering: from a case study of $\mathrm{ZnO}$ to other ceramics. Scr. Mater. 146, 260-266 (2018).

20. Nie, J. et al. Two-step flash sintering of $\mathrm{ZnO}$ : fast densification with suppressed grain growth. Scr. Mater. 141, 6-9 (2017).

21. Todd, R. I. et al. Electrical characteristics of flash sintering: thermal runaway of Joule heating. J. Eur. Ceram. Soc. 35, 1865-1877 (2015).

22. Jha, S. K. \& Raj, R. The effect of electric field on sintering and electric conductivity of titania. J. Am. Ceram. Soc. 97, 527-534 (2014).

23. Cologna, M., Francis, J. S. C. \& Raj, R. Field assisted and flash sintering of alumina and its relationship to conductivity and MgO-doping. J. Eur. Ceram. Soc. 31, 2827-2837 (2011).

24. Li, J. et al. Sintering behavior of samarium doped ceria under DC electric field. Ceram. Int. 44, 2470-2477 (2018).

25. Jha, S. K., Terauds, K., Lebrun, J. M. \& Raj, R. Beyond flash sintering in $3 \mathrm{~mol}$ $\%$ yttria stabilized zirconia. J. Ceram. Soc. Jpn 124, 283-288 (2016).

26. Swain, M. V. Shape memory behaviour in partially stabilized zirconia ceramics. Nature 322, 234-236 (1986).

27. $\mathrm{Du}, \mathrm{Z}$. et al. Size effects and shape memory properties in $\mathrm{ZrO}_{2}$ ceramic microand nano-pillars. Scr. Mater. 101, 40-43 (2015).
28. Camposilvan, E. \& Anglada, M. Size and plasticity effects in zirconia micropillars compression. Acta Mater. 103, 882-892 (2016).

29. Zeng, M. X., Lai, A., Gan, C. L. \& Schuh, C. A. Crystal orientation dependence of the stress-induced martensitic transformation in zirconia-based shape memory ceramics. Acta Mater. 116, 124-135 (2016)

30. $\mathrm{Du}, \mathrm{Z}$. et al. Superelasticity in micro-scale shape memory ceramic particles. Acta Mater. 123, 255-263 (2017)

31. Korte, S., Barnard, J. S., Stearn, R. J. \& Clegg, W. J. Deformation of silicon insights from microcompression testing at $25-500{ }^{\circ} \mathrm{C}$. Int. J. Plast. 27, 1853-1866 (2011)

32. Korte, S. \& Clegg, W. J. Micropillar compression of ceramics at elevated temperatures. Scr. Mater. 60, 807-810 (2009).

33. Todd, R. I. Flash sintering of ceramics: a short review. In Proc. IV Advanced Ceramics and Applications Conference (eds Gadow, R., Mitic, V. \& Lee, B.) 1-12 (Atlantis Press, Paris, 2017).

34. Abrams, H. Grain size measurement by the intercept method. Metallography 4, 59-78 (1971)

35. Sakuma, T., Yoshizawa, Y. I. \& Suto, H. The microstructure and mechanical properties of yttria-stabilized zirconia prepared by arc-melting. J. Mater. Sci. 20, 2399-2407 (1985).

36. Morita, K. \& Hiraga, K. Deformed substructures in fine-grained tetragonal zirconia. Philos. Mag. Lett. 81, 311-319 (2001).

37. Eshelby, J. D., Frank, F. C. \& Nabarro, F. R. N. The equilibrium of linear arrays of dislocation. Philos. Mag. 42, 351-364 (1951).

38. Callister, W. D. \& Rethwisch, D. G. Materials Science and Engineering 197-233 (John Wiley \& Sons, NJ, 2011).

39. Montagne, A., Pathak, S., Maeder, X. \& Michler, J. Plasticity and fracture of sapphire at room temperature: load-controlled microcompression of four different orientations. Ceram. Int. 40, 2083-2090 (2014).

40. Kiani, S. et al. Dislocation glide-controlled room-temperature plasticity in $6 \mathrm{H}-$ SiC single crystals. Acta Mater. 80, 400-406 (2014).

41. Lankford, J., Page, R. A. \& Rabenberg, L. Deformation mechanisms in yttriastabilized zirconia. J. Mater. Sci. 23, 4144-4156 (1988).

42. Narayan, J. A new mechanism for field-assisted processing and flash sintering of materials. Scr. Mater. 69, 107-111 (2013).

43. Morscher, G. N., Pirouz, P. \& Heuer, A. H. Temperature dependence of hardness in yttria-stabilized zirconia single crystals. J. Am. Ceram. Soc. 74, 491-500 (1991).

44. Zhao, X. S., Shang, S. L., Liu, Z. K. \& Shen, J. Y. Elastic properties of cubic, tetragonal and monoclinic $\mathrm{ZrO}_{2}$ from first-principles calculations. J. Nucl. Mater. 415, 13-17 (2011).

45. Fogaing, E. Y., Lorgouilloux, Y., Huger, M. \& Gault, C. P. Young's modulus of zirconia at high temperature. J. Mater. Sci. 41, 7663-7666 (2006).

46. Ren, X. \& Pan, W. Mechanical properties of high-temperature-degraded yttria-stabilized zirconia. Acta Mater. 69, 397-406 (2014).

47. Becher, P. F. \& Swain, M. V. Grain size dependent transformation behavior in polycrystalline tetragonal zirconia. J. Am. Ceram. Soc. 75, 493-502 (1992),

48. Lange, F. F. Transformation toughening part 1 size effects associated with the thermodynamics of constrained transformations. J. Mater. Sci. 17, 225-234 (1982).

49. Camposilvan, E. \& Anglada, M. Micropillar compression inside zirconia degraded layer. J. Eur. Ceram. Soc. 35, 4051-4058 (2015).

50. Subhash, G. \& Nemat-Nasser, S. Dynamic stress-induced transformation and texture formation in uniaxial compression of zirconia ceramics. J. Am. Ceram. Soc. 76, 153-165 (1993).

51. Dickinson, G. R., Petorak, C., Bowman, K. \& Trice, R. W. Stress relaxation of compression loaded plasma-sprayed $7 \mathrm{wt} \% \mathrm{Y}_{2} \mathrm{O}_{3}-\mathrm{ZrO}_{2}$ stand-alone coatings. J. Am. Ceram. Soc. 88, 2202-2208 (2005).

52. Reid, A. C. E. et al. Modelling microstructures with OOF2. Int. J. Mater. Prod. Technol. 35, 361-373 (2009).

\section{Acknowledgements}

The authors are thankful for the financial support by the U.S. Office of Naval Research N00014-17-1-2087 (sample preparation and in situ SEM), N0014-16-1-2778 (TEM) and partly by N0014-16-S-BA10. Q.L. and S.X. acknowledge partial financial support from the Department of Energy OBES (Grant No. DE-SC0016337) on performing micropillar preparation experiments. Z.F. acknowledges the financial support from NSF-CMMI (Grant No. 1161978). J.L. is partly supported by NSF-CMMI (CMMI-1728419). We also acknowledge access to the Life Science Microscopy Facility and the microscopy center in the School of Materials Engineering at Purdue University.

\section{Author contributions}

J.C. and Q.L. fabricated the YSZ micropillars and J.C., Q.L., Z.F., and S.X. performed the temperature-dependent compression experiments. J.C., Q.L., Haiyan.W., and X.Z. conducted data analyses and manuscript preparations. Q.L. and Han.W. collected the SEM imaging and Han.W., J.L., and Haiyan.W. carried out TEM experiments. T.B.H. and A.K.M. 
prepared the sintered specimens and involved in the discussion and data analysis. K.S.N.V. and R.E.G. helped with data analysis and FEM calculations.

\section{Additional information}

Supplementary Information accompanies this paper at https://doi.org/10.1038/s41467018-04333-2.

Competing interests: The authors declare no competing interests.

Reprints and permission information is available online at http://npg.nature.com/ reprintsandpermissions/

Publisher's note: Springer Nature remains neutral with regard to jurisdictional claims in published maps and institutional affiliations. (c) Open Access This article is licensed under a Creative Commons Attribution 4.0 International License, which permits use, sharing, adaptation, distribution and reproduction in any medium or format, as long as you give appropriate credit to the original author(s) and the source, provide a link to the Creative Commons license, and indicate if changes were made. The images or other third party material in this article are included in the article's Creative Commons license, unless indicated otherwise in a credit line to the material. If material is not included in the article's Creative Commons license and your intended use is not permitted by statutory regulation or exceeds the permitted use, you will need to obtain permission directly from the copyright holder. To view a copy of this license, visit http://creativecommons.org/ licenses/by/4.0/.

(C) The Author(s) 2018 